\title{
The Change in ELT Pre-service Teachers' Cognition During Teaching Practicum
}

\author{
İlknur Yüksel ${ }^{1}$, Banu Çiçek Başaran ${ }^{1}$ \\ ${ }^{1}$ ELT Department, Education Faculty, Eskişehir Osmangazi University, Turkey \\ Correspondence: İlknur Yüksel, ELT Department, Education Faculty, Eskişehir Osmangazi University, Turkey.
}

Received: July 9, 2019 Accepted: July 30, $2019 \quad$ Online Published: August 5, 2019

doi:10.11114/jets.v7i10.4425 URL: https://doi.org/10.11114/jets.v7i10.4425

\begin{abstract}
The aim of this study was to examine the change of ELT pre-service teachers' cognition during teaching practicum uncovering their beliefs regarding language teaching, being a teacher and dynamics of practicum. To adopt a comprehensive perspective on how the participants' cognition evolved as a result of practicum, qualitative research design with open-ended surveys before and after the practicum process was conducted with ELT pre-service teachers. The findings were evaluated and discussed in terms of a certain framework with change categories of Cabaroglu and Roberts (2000). The results indicated that the practicum is apt to change the pre-service teachers' beliefs through awareness, elaboration, addition, re-ordering and reversal as a result of practicum. As the results suggest the practicum provides a real-life context for the pre-service teachers, they could adopt their grounded beliefs, which were acquired as language learners, and transform them into language teachers' beliefs. As the participants stated the mentor, supervisor and classroom dynamics enabled such transformation, mostly in positive route. However, there are some stable beliefs that did not change during the practicum. The participants kept some functioning beliefs for their teaching practice. The results implied the complexities of the practicum process on the pre-service teachers' cognition.
\end{abstract}

Keywords: teachers' cognition, practicum, pre-service teachers

\section{Introduction}

Teaching is a cognitive activity embodied with what teachers know, believe and think. Borg (2003) explained this cognitive dimension as "teachers are active, thinking decision-makers who make instructional choices by drawing on complex practically-oriented, personalized and context-sensitive networks of knowledge, thoughts and beliefs" (p.81). As an intangible dimension of teaching; teacher cognition is defined as "pre- or in-service teachers' reflections; beliefs and knowledge about teaching, students, and content and awareness of problem-solving strategies endemic to classroom teaching" (Kagan, 1992; p.419). Teachers' cognition is widely agreed to have crucial and influential roles in shaping teachers' behavior, teaching style and their approach to teaching and learning (Borg, 2005). Addressing to this significance, different studies have been conducted on the teachers' cognition (Zheng, 2009), the factors and variables forming cognition (Gürsoy, 2013; Jamalzadeh \& Shahsavar, 2014), the impacts of beliefs on teaching performances (Peacock, 2001).

The studies so far reached to the consensus that the pre-service teachers' cognition functions as the predictor for their teaching performance (Peacock, 2001; Borg, 2003; Tang, Lee \& Chun, 2012). In fact, pre-service teachers started their training with grounded beliefs that they gained as a result of their experience as language learners so far (Kagan, 1990) and these beliefs endure as filters to perceive, internalize and apply the new information and perspectives they are exposed during their training (Borg, 2006). In addition to the courses offered at the program and other variables encountered during training, teaching practicum is of primary importance to shape unrefined beliefs of pre-service teachers and transform their roles from language learners into language teachers for the "real-life" teaching situations (Pajares, 1992; Tang, 2004). However, the process of such 'change' in pre-service teachers' cognition has been a controversial research focus in literature.

Although the phenomenon of pre-service teachers' cognition has been studied in different contexts (Borg, 2006; 2003), most of them have been constrained with the 'content' of pre-service teachers' cognition; what cognitions; beliefs, they have (Gürsoy, 2013), the process of change in their cognition during training, practicum and career has been neglected to a certain extent (Borg, 2009; Gürsoy, 2012; Debreli, 2012), particularly the process of cognition change during teaching practicum, which is agreed as touchstone for teaching career, has remained mostly unexplored (Yuan \& Lee, 
2014). Addressing to this gap, the present study aimed to examine the change of ELT pre-service teachers' cognition during teaching practicum uncovering their beliefs regarding language teaching, being a teacher and dynamics of practicum. To adopt a systematic approach to evaluate the change in pre-service teachers' cognition, Cabaroglu and Roberts' (2000) framework was used in the study to track the change during the teaching practicum.

\subsection{Change in Pre-service Teachers' Cognition and Practicum}

To ensure the quality in teaching, the most important step is to focus on teacher. Teachers' cognition is of great importance for qualified teaching performance. Therefore, the pre-service teachers' beliefs, cognition, have been researched so far to comprehend and predict what they believe and how they will teach. The practicum is the first and most important arena that pre-service teachers' theoretical and practical knowledge are tested and their beliefs are highly influential during this process (Borg, 2015; Yu \& Lee, 2017). Although it has been studied how pre-service teachers' beliefs influence their teaching and learning process (Gürsoy, 2013), it has not been questioned adequately how the teaching process, practicum, influences pre-service teachers. The limited studies on the change of teachers' cognition have contradictory findings. Challenging the assumptions that the pre-service teachers' beliefs are inflexible (Kagan, 1992; Peacock, 2001) and these beliefs remain stable (Borg, 2005) even resistant against teacher education program and teaching practicum (Kunt \& Ozdemir, 2010; ), some recent studies detected noteworthy changes in pre-service teachers' cognition particularly as a result of teaching practicum (Cabaroglu \& Roberts, 2000; Gürsoy, 2012; Debreli, 2012; Yuan \& Lee, 2014; Sheridan, 2016; Kavanoz, Yüksel \& Varol, 2017).

As one of the pioneering studies, Caboroglu and Roberts (2000) challenged the claim of inflexible teachers' beliefs through a naturalistic inquiry with 20 students during one-year long program. The findings indicated that the pre-service teachers changed some of their beliefs. To interpret the process of change, Cabaroglu and Roberts (2000) proposed a framework with 11 indicators tracking how pre-service teachers evolved their beliefs regarding teaching and learning. Adopting the same framework, Yuan and Lee (2014) conducted a case study to explore the process of changes in the pre-service teachers' beliefs considering the sociocultural factors triggering the change. The results confirmed the gradual and cumulative change in the beliefs and like Cabaroğlu and Roberts (2000), certain processes such as confirmation, realization, elaboration, modification, integration and disagreement were observed in the study.

The practicum is the keystone of teacher training as it provides real-life opportunities for pre-service teachers' professional learning and development. Through teaching practice at actual classroom and scaffolding of mentor and supervisors, pre-service teachers could improve their practical knowledge and consolidate theoretical knowledge, most importantly they could reflect on their grounded values and beliefs (Gebhard, 2009; Yuan \& Lee, 2014). The practicum enables pre-service teachers adjust and transform their pre-established beliefs regarding learning and teaching into fact-oriented and actual practices in their further career (Pajares, 1992; Richards \& Lockhart, 1994; Paakkari, Tynjala, Torppa, Villber \& Kannas, 2015). Thus, the course of practicum is the appropriate context to explore the change of pre-service teachers' beliefs.

Considering the significance of practicum courses in teacher education program and the vital roles of teacher cognitions in shaping pre-service teachers' teaching performance and future career, this study aimed to examine the change of ELT pre-service teachers' cognition through the practicum courses. Rather than the content of teacher cognition, the process of change in teacher cognition and its relationship with practicum were focused in this study.

\section{Method}

\subsection{Research Design}

Qualitative research design was adopted in this study to examine the phenomenon over a period of time in depth (Bryman, 2008). Qualitative research allows researchers to get at the inner experience of participants, to determine how meanings are formed through and in culture, and to discover rather than test variables (Corbin \& Strauss, 2008) To have a comprehensive approach on the potential change on the pre-service teachers' cognition, pre and post surveys with open-ended questions were conducted at the beginning and end of the practicum. Through qualitative survey research, it was aimed to examine the change of the pre-service teachers' cognition during the practicum.

Addressing to this aim, the following research questions were asked in this study:

1. What are the ELT pre-service teachers' cognition regarding teaching before the teaching practicum?

2. How does the ELT pre-service teachers' cognition change during the teaching practicum?

\subsection{Context and Participants}

Through purposeful sampling, which is the widely used technique in qualitative research design in order to involve the individual with knowledge and experience about the phenomenon under research (Creswell, 2012), 61 senior students attending to ELT department of Eskisehir Osmangazi University, Turkey, were included in the study. As the research focus of the study is to detect the potential change of the participants' cognition during the practicum, the criterion of 
sampling is to involve the ones attending to the practicum courses. To track the changes, the pre and post surveys were given to the participants, the findings obtained from the ones, 28 pre-service teachers, who completed both surveys during the practicum were taken into consideration for the data analysis.

In ELT program, upon successfully completing six terms of courses about English literature, linguistics, translation, language teaching methodology and vocational courses, the students are required to take a school experience course in the seventh semester. In this course, the pre-service teachers visit public and private schools for 14 weeks to observe and practice real English language teaching experience. In the final term, the pre-service teachers start taking the practice teaching course, practicum, which provides a more comprehensive teaching experience for the students. During the process of data collection, the participants had already completed the initial school experience course and they were in the process of taking practice teaching course, practicum. As the requirement of the practicum, the participants were assigned to the state schools as elementary, secondary and high school and they are required to attend 6 hours a week for observation, macro teaching practice. Each participant is to prepare and teach $40 \mathrm{~min}$, full time teaching lesson with the guidance of supervisor under the observation of the mentors.

\subsection{Data Collection Instrument}

As a qualitative research, the present study used a survey with open-ended question given at beginning and end of the practicum and reflections written regularly for fourteen weeks for each academic term (fall and spring) by each pre-service teacher.

The survey was developed by one of the researchers as a result of literature review and related studies. It contains 13 open-questions inquiring the participant's beliefs about language teaching, being a teacher and classroom teaching dynamics. The participants were asked to complete an online survey about practicum process. They completed the same survey at the beginning of the term before they started their practicum process and at the end of the term after they completed the practicum. Out of 35 pre-service teachers, 28 of them completed the first survey and 32 of them completed the second survey. Upon collating the survey data, it is seen that the number of participants who completed both of the surveys was 28 ( 5 male and 23 female students).

Rather than starting the data collection process at the beginning of the seventh term, the researchers administered the survey at the beginning of the eighth term to help students experience a "real classroom" atmosphere at practicum course. In order for researchers to better understand the belief change process, the participants needed to develop some sense for their teacher identity. It is for this reason that the data collection was carried out after the pre-service teachers completed school experience course in the preceding term.

\subsection{Data Analysis}

Data analysis was carried out according to the categories suggested by Cabaroglu and Roberts (2000). They identified ten categories for teacher belief development. A summary of the categories can be viewed from Table 1 below. First and second survey data of 28 participants were organized and compared and contrasted to understand and evaluate the change in their beliefs upon completing the practicum process.

Table 1. Summary of belief change processes (Cabaroglu \& Roberts, 2000, p. 393-398)

\begin{tabular}{|c|c|}
\hline Categories & Process explained \\
\hline Awareness/realization & $\begin{array}{l}\text { The student teacher realises or becomes more fully aware of a construct, idea or } \\
\text { process. As a result, s/he accepts and understands it better. }\end{array}$ \\
\hline Consolidation/confirmation & $\begin{array}{l}\text { A student teacher perceives a consistency between her/his existing beliefs and } \\
\text { newly presented information, so that they become more established. }\end{array}$ \\
\hline Elaboration/polishing & $\begin{array}{l}\text { Elaboration (or polishing) refers to the process of refining existing beliefs so that } \\
\text { they elaborate relevant knowledge and connect with new input. }\end{array}$ \\
\hline Addition & $\begin{array}{l}\text { This term refers to the addition of new constructs. This process seems to take place } \\
\text { after the participant recognises new information as useful in making sense of a } \\
\text { learning/teaching issue. }\end{array}$ \\
\hline Re-ordering & $\begin{array}{l}\text { This refers to the rearrangement of beliefs according to importance, both as } \\
\text { prioritisation and as weakening. }\end{array}$ \\
\hline Re-labeling & $\begin{array}{l}\text { A student teacher perceives no change in the construct or belief but adopts a new } \\
\text { term for it, usually after having read, or heard the technical term. }\end{array}$ \\
\hline Linking up & The student teacher makes a new connection between two constructs. \\
\hline Disagreement & $\begin{array}{l}\text { One way of resolving a conflict between one's current beliefs and new experience } \\
\text { can be to move away from the old belief toward a new one. }\end{array}$ \\
\hline Reversal & $\begin{array}{l}\text { It refers to change where the participant is moving to the adoption of a belief that } \\
\text { seems to deny a former one. }\end{array}$ \\
\hline Pseudo change & $\begin{array}{l}\text { This refers to a process in which a belief continues to be important to the person, } \\
\text { but is perceived as not immediately relevant or applicable. }\end{array}$ \\
\hline No change & In this case participants assess no change in their beliefs. \\
\hline
\end{tabular}




\section{Results}

First Survey

Upon analyzing the data gathered through the first round of survey, it was seen that almost half of the participants had a tendency to perceive themselves as somewhat incompetent with regards to classroom management. The other half reported that they are confident and they believe in their teaching skills and that they can establish good relationship with the students.

Their beliefs about linking the theory and practice was mixed. When asked which aspects of theories they have studied could be put into practice, pre-service teachers replied it depends on the learner profile. While there were some participants who stated one method or approach for teaching English (such as TPR, CLT, Natural Approach, etc.), the recurring theme was following eclectic methodology.

The student teachers were also asked about their teaching philosophies. As can be expected, almost all of the participants had different beliefs about this issue. Student-tailored teaching, enhancing autonomous learners, teacher as a guide/facilitator, being fair and honest were some of the themes that were identified for this question.

Their expectations from the university supervisor was three-fold: giving feedback, showing support, and evaluating the mistakes of the pre-service teachers. This shows the importance of rapport between supervisor and pre-service teachers and the significance of providing feedback. The participants believe that they can improve themselves through constructive feedback and that they are open to positive criticism. When it comes to their expectations from the mentor teacher in schools, the results were similar. The pre-service teachers believe that the mentor teacher should be supportive, and they should provide feedback after the in-class tasks.

Pre-service teachers were also asked to write the three points that they wanted to be evaluated during practice teaching. Most common themes were classroom management, teacher-student relationship and material use. Since the pre-service teachers had difficulties with classroom management, they wanted to be evaluated on this point and they want to receive feedback afterwards. The participants also value student-teacher relationship and they want the supervisors' and the mentors' opinions about this topic. Using different types of materials and activities was another important point for the participants.

The biggest fear of pre-service teachers is classroom management. They mentioned things like crying students, unmotivated learners, and highly energetic young learners. The points they were most confident about themselves was their relationship with the students, using creative materials, their motivation and fairness. Some of the participants also mentioned classroom management as their strongest points.

Majority of the pre-service teachers believe that practice teaching course provides them a change to gain experience, which will help them throughout their future careers. They also believe that this course helps them to improve their classroom management skills and provide opportunities for networking.

Their beliefs about the courses they had taken in the teacher-training program were quite positive. Almost all of the participants believe that the undergraduate courses were helpful in preparing them for the practicum process and their future career. On the other hand, few students were not satisfied with the courses and found them too theoretical.

When asked specifically which courses contributed to their practice teaching performance, majority of them listed the following courses as the most beneficial ones: Methodology course, Teaching English to Young Learners, Approaches to ELT, Language Teaching Materials Adaptation and Development. Again, some students believe that the courses should be more practical so that they can feel more confident when they are taking practicum courses.

To summarize the most significant results of the first survey, it can be said that at the beginning of the practice teaching process the half of the participants were quite confident in their teaching skills while the other half believed that they had problems with classroom management. Their expectations from the supervisors and the mentors were similar: feedback and support. They also believed that they wanted to be evaluated for their classroom management skills and their ability to establish a good relationship with the students. Furthermore, their biggest fear in relation to practice teaching was classroom management while they felt themselves most confident in was building good student-teacher relationship. The participants' common belief was that practice teaching helps them to gain teaching experience before they start their careers. Similarly, they believe that the courses they had taken until the final semester of the program contributed to their development as teachers.

\section{Second Survey}

Towards the end of the semester, the participants were asked to complete the same survey again. The data gathered through the second round of data collection were analyzed and then categorized based on the ones suggested by Cabaroglu and Roberts (2000). While analyzing, first and second survey data were collated and then compared for each 
of the 28 participants for each of the item in the survey to better observe if there was any change in their beliefs. The overall analysis suggests that the student teachers experienced either "no change" or "reversal" in their beliefs. "Consolidation/confirmation", "re-labeling", "linking-up", and "disagreement" were the empty category for this participant group. In other words, pre-service teachers did not experience these belief development processes. The results of the second survey are presented in accordance with the categories. A summary of the frequencies for each of the belief development process can be observed from the Table 2 .

Table 2. Summary of the number of incidents for each of the belief development processes.

\begin{tabular}{|c|c|c|c|c|c|c|c|c|c|c|c|}
\hline 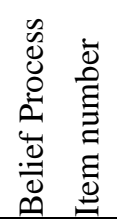 & 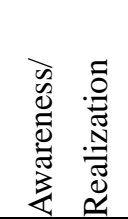 & 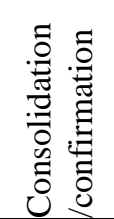 & 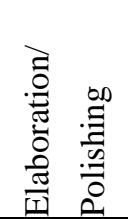 & : & 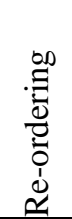 & 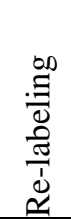 & 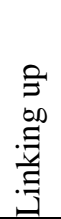 & 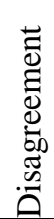 & $\begin{array}{l}\overline{\widetilde{D}} \\
\overrightarrow{0} \\
\bar{d} \\
\widetilde{\alpha}\end{array}$ & 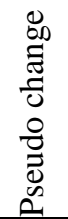 & $\begin{array}{l}0 \\
60 \\
\bar{\Xi} \\
\overline{0} \\
0 \\
0\end{array}$ \\
\hline 3 & 1 & & 7 & 1 & & & & & 6 & 3 & 10 \\
\hline 4 & & & 4 & 6 & & & & & 10 & 1 & 6 \\
\hline 5 & & & 2 & 2 & 3 & & & & 16 & 4 & 1 \\
\hline 6 & & & & 1 & & & & & 9 & & 18 \\
\hline 7 & & & 1 & 4 & 1 & & & & 9 & 2 & 11 \\
\hline 8 & & & & & 25 & & & & & & 17 \\
\hline 9 & & & 1 & 1 & 4 & & & & 12 & 1 & 8 \\
\hline 10 & & & 2 & 1 & 3 & & & & 11 & 3 & 8 \\
\hline 11 & & & 2 & 4 & 1 & & & & 1 & 7 & 12 \\
\hline 12 & 2 & & 4 & 3 & 1 & & & & 3 & & 13 \\
\hline 13 & & & & 8 & 4 & & & & 1 & 1 & 14 \\
\hline Total: & 3 & 0 & 23 & 31 & 42 & 0 & 0 & 0 & 78 & 22 & 118 \\
\hline
\end{tabular}

Awareness/realization

For this belief change process, there were only three instances in the data. One of the participants (\#3) expressed her awareness related with her self-development as a teacher:

At the beginning, I didn't know what to do with young learners. Then, I have learnt their interests, abilities, likes and dislikes. I was improved my teaching as I observed them. I'm qualified enough. My relationship with students, interest to my job, using different methods and techniques are my strengths. On the other hand, I'm a strict teacher. I have to be more democratic in the class. [sic] (Participant \#3)

Other two participants shared their belief development concerning the courses they had taken in the training program and their effects on their future careers.

Yes. I have learnt to look at the things from a child's view and prepare lessons by taking into consideration their needs [sic] (Participant \#8)

Yes, most of them prepared us to the T.P. We went to the practicum as aware of some truths thanks to these lessons. [sic] (Participant \#6)

\section{Elaboration/polishing}

There were a few instances of this type of belief development for the participants. Some expressed this development in relation to the courses they had taken, contribution of practice teaching to their career, their strongest points, their fears, expectations from the mentor teachers, their teaching philosophies, establishing the link between theory and practice and self-development as teachers. The following participants had a deeper understanding of their abilities as a teacher after the practicum process.

During my teaching practice, I learnt new things each week. Negative experience at this time caused to change my mind and developed me with a positive way. I am a confident person and I believe that I will be very professional at this job this is my strength. I have some Hesitation about foreign language-that's my weakness [sic] (Participant \#22) 
I think I am qualified at least as a decent teacher. I think my strongest trait is I know how a student thinks, I hope I don't lose it in later years. My weaknesses are, I can sometimes lose my patience and it is demoralizing, also I can't prepare any material at all. I just don't have the talent for arts and crafts unfortunately. [sic] (Participant \#20)

I think that I have been quite experienced for a year. I am really lucky to practice both at high school and secondary school. I think that I am quite qualified as I have studied a lot of things particularly pronunciation. As my strengths, I can say that I am tolerated and patient. I am careful at pronunciation, too. In addition, I also can say my voice is quite high and changeable. As weaknesses, I had a lot of problems in time management. Furthermore, speaking slowly is quite hard for me. [sic] (Participant \#28)

\section{Addition}

Similarly, quite a few student teachers expressed their beliefs with regards to different areas by integrating new ones. After the practicum process, the participants were able to increase the number of courses they deemed beneficial for their future careers and teaching performances. Before the practicum, they provided more general answers with regards to their beliefs rather than giving specifics. After the practicum course, their beliefs about the effectiveness of the undergraduate courses on their teaching performance is changed. They were better able to see the link between specific courses and their future careers. For instance, for the question "Which aspects of theory you have studied could be put into practice during Teaching Practice?", Participant 2 wrote "most of them" in the first questionnaire. In the second one, he wrote "the stages, the kind of materials, the intelligence types of learners". While preserving their old beliefs, the student teachers were able to add new beliefs upon completing the practicum process.

\section{Re-ordering}

For this category, 25 participants out of 28 expressed their beliefs about the points they wanted to be evaluated. They were asked to list three items/points for evaluation. Majority of them changed their beliefs about this issue and created a new "top three list" for the areas they wanted to be evaluated. Upon analyzing the two surveys together, it is seen that although "classroom management" was still in the list, as the most important one, the other two items showed difference before and after the practicum. After the practicum, the participants seemed to realize the importance of material, interaction with students, fluent English for their teaching performance. So, they re-order the range of important teaching skill as they experience the real classrooms and students.

\section{Reversal}

After "no change" category, this belief development process was highly observed in the data. For almost all of the questions, the participants showed some form of reversal. In other words, they either abandoned their previous beliefs or developed new ones that are just the opposite or they revised their beliefs and replaced them with more practical ones. Reversal category is highly observed in their beliefs about their biggest fear, their best skill, their teaching philosophy and establishing the link between theory and practice. For example, Participant 4 wrote "depends on the students" for the aspects of theory that can be out into practice, before the practicum experience. She wrote "communicative approach" for the same question after the practicum. Although these two answers are not completely at the opposite ends, the revision of belief can be observed. Similarly, before the practicum, Participant 13 wrote "Albert Einstein says 'Everyone is a genius. But if you judge a fish by its ability to climb a tree, it will live its whole life believing that it is stupid.' My job as a teacher is to help students discover that genius within my students." [sic] for her teaching philosophy. After the practicum, she stated that her teaching philosophy was "To give the students a useful thought in their life". Furthermore, Participant 21 evaluated his skills as a teacher and wrote "I'm not qualified enough as a teacher" before the practicum; while at the end he stated that "I'm qualified enough for teaching".

\section{Pseudo change}

Few of the participants were observed to have pseudo changes in their beliefs. Although they appeared to be talking about a difference in their beliefs, they were expressing the same things. As it was the case for other categories, for this category, the results of first and second surveys were compared.

I think it gives an idea about your choices. For example, i have always wanted to teach at an elementary school. But for the first practicum in a middle school, i realized it is very tiring. I'm happy that i did the practice for both high school and middle school. [sic] (Participant \#3, first survey)

It lets me to know myself through experience. It gives me an idea about student profiles and my wants or abilities. [sic] (Participant \#3, second survey)

For "How would Teaching Practice contribute to your future career?", Participant 3 stated that teaching practice gives her an opportunity to work with different learner profiles both in the first and in the second survey. The same participant also shared her beliefs about her teaching philosophy as follows: 
I believe I should transfer the information to my students systematically. While doing this, I shouldn't ignore their feelings, mood, character and life. I will teach English as far as I can but I will not look at my students as they are a machine. [sic] (Participant \#3, first survey)

I believe learning is different for everybody. Everybody see the world from different perspective and learn something from that perspective if it lets. I will try to reach every student and find what is their perspective. I will share my own. This is my philosophy. [sic] (Participant \#3, second survey)

As can be inferred from the data above, in its essence, the pre-service teachers talks about the importance of individual differences of learners.

\section{No change}

With 118 instances, this belief development process was the most frequent one in this study. For all the items in the survey, the participants showed no change in their beliefs. As mentioned above, when asked for their "top three list" for the areas they wanted to be observed, more than half of the participants kept "classroom management" on their list in the first and in the second survey. Similarly, pre-service teachers' beliefs about their expectations from the supervisors and the mentors showed no change after practicum. For the items inquiring about the participants' beliefs in practice teaching and their future careers, majority of them showed no difference. They believe that practicum courses provide them an opportunity to experience "real teaching environment" and that the courses they had completed in the undergraduate program helped them to improve themselves as teachers.

\section{Discussion}

The aim of this study was to examine the change of ELT pre-service teachers' cognition during teaching practicum uncovering their beliefs regarding language teaching, being a teacher and dynamics of practicum. To adopt a comprehensive perspective on the results, the findings were evaluated and discussed in terms of a certain framework with 11 categories, which were validated and used by Cabaroglu and Roberts (2000) and Yu \& Lee (2017). Through the lenses of each category, the influence of practicum on teachers' cognition could be emerged and the question of whether the pre-service teachers' rooted beliefs could change or not could be answered considering certain categories.

When the pre and post survey results were examined, it was generally seen that the practicum is apt to change the pre-service teachers' beliefs. The results indicated that some of the participants changed their process through awareness, elaboration, addition, re-ordering and reversal as a result of practicum. Thus, contrary to the views of Peacock (2001) and Mattheoudakis (2007), the pre-service teachers' teaching practice during practicum had certain influence on their beliefs at least in terms of some change processes. In other words, the pre-service teachers' cognition is not 'inflexible' as Kagan (1992) claimed but certain beliefs could change through some developmental processes. Therefore, it can be claimed that as pre-service teachers experience the classroom reality and test their knowledge and realize their beliefs during teaching practice, they tend to change and develop some beliefs.

Nevertheless, the most striking result of the study was the outnumber of no change category, which indicates that most of the participants did not change their beliefs despite the practicum process. This result complies with Peacock's (2001) longitudinal study which also emphasized the inflexibility of preservice teachers' beliefs. However, as Mattheoudakis (2007) and Gürsoy (2013) explained the changes in beliefs require time and there is a kind of threshold at which they would review and modify their beliefs. In this study, it was seen that the practicum triggered some participants to reconceptualize and modify their beliefs particularly through elaboration, addition and reordering but for the other participants, it can be said that they need more experience and time to evaluate their beliefs. As a matter of fact, some participants kept some beliefs because they thought they were useful and effective for their teaching practice and the practicum process showed that their belief is functioning. For instance, some participants appreciated the classroom management as the most important competency before the practicum and such cognition did not change, in fact it seemed that it was grounded at the end of the practicum. Thus, it can be claimed that the practicum process helped the pre-service teachers reason and reassure their cognition with the help of experience.

Additionally, there are some participants who thought that they changed their beliefs but did not change at all. They were categorized under pseudo change. The answers analyzed under this category showed that these participants just started to question their beliefs but they did not come up with the appropriate reasoning and modification. As Caboroglu and Roberts (2001) underlined, supervisors and implementation of practicum are significant to help preservice teachers confront the pre-existing beliefs and gain awareness to restructure. As a matter of fact, the findings at the first and second survey showed the participants valued the supervisors' feedback and opinions and their beliefs about the supervisors remained no change. If they had received more feedback or support from the supervisor during the practicum, they could be more aware of their beliefs and change their beliefs consciously. Thus, it can be claimed that the supervisors and implementation of practicum course are important to facilitate positive evolvement of pre-service teachers' beliefs. 
When the emerged changes in beliefs were examined, it could be seen that the pre-service teachers gained deeper understanding of the classroom dynamics and they gained more awareness about teaching-learning processes as they observed real classrooms and teach students at actual classrooms. The findings under the category of elaboration and reordering indicated such change. The influence of practicum and real classroom and such potential change observed in this study were also put forth by Debreli (2016) and Tang, Lee \& Chun (2012). They also observed how teaching practice reshaped the pre-service teachers' beliefs. As a result of implementing the teaching methods during the practicum, the pre-service teachers could re-conceptualize their beliefs. For example, in the present study; although most of the participants knew about the classroom management, they became more aware of how vital classroom management for their teaching performances is at the end of the practicum and most of them reordered the classroom management as the most important skill. Additionally, the findings under the category addition showed that the practicum contributed new beliefs to the pre-service teachers as they realized the importance of teaching stages, students' needs, intelligence types and material types.

Furthermore, the results regarding the reversal change in the pre-service teachers' beliefs also indicated how the practicum could change the cognition, in deed how the pre-service teachers' self-confidence is improved. After the practicum, some participants gained confidence in their teaching qualifications and they believed in themselves to touch their students' lives. Thus, it can be stated that the practicum process leads to fix and modify some beliefs in more reassuring and supportive manner. This finding is consistent with Cabaroglu and Roberts' (2000) claims that rather than disagreement, the pre-service teachers tend to reverse and adopt the opposite of the former beliefs. The effect of context on such linear change should be taken into consideration. The practicum context, the support of mentor and supervisors, the opportunities to put theory into practice, the good relationship with students and classroom dynamics are some factors that could support positive evolvement of the pre-service teachers' grounded beliefs (Debreli, 2006). The findings of the present study also revealed that the practicum triggered some positive evolvement on teacher cognition, in a way that they developed elaboration, awareness, self-confidence in their teaching practice. It should be also noted that the pre-service teachers still kept most of their beliefs, as no change category showed, however, the practicum process allowed them to question their previous beliefs; develop an awareness to put the theory into practice and reconceptualize their beliefs according to personal experience with the school, class and students.

\section{Conclusion}

The results of the study put forth the potential effect of the practicum and teaching practice on the evolvement of the pre-service teachers' cognition. By discussing the change process under categories, the present study enables to track the change in their beliefs and uncover their thinking processes during the practicum. As the results suggest the practicum provides a real-life context for the pre-service teachers, they adopt their grounded beliefs, which were acquired as language learners, and transform them into language teachers' beliefs. As the participants stated the mentor, supervisor and classroom dynamics enabled such transformation, mostly in positive route. However, there are some stable beliefs that did not change during the practicum. The participants kept some functioning beliefs for their teaching practice. The results implied the complexities of the practicum process on the pre-service teachers' cognition. Thus, the reasons and factors that triggered such potential changes on the teachers' cognition could be investigated to have a deeper insight such change process. Additionally, to track the positive evolvement of pre-service teachers' cognition, their teaching practice and implementations could be observed and the concrete indicators of the change could be asserted.

\section{References}

Borg S. (2003). Teacher cognition in language teaching: a review of research on what language teachers think, know, believe, and do. Language Teaching, 36(2), 81-109. https://doi.org/10.1017/S0261444803001903

Borg, M. (2005). A case study of the development in pedagogic thinking of a pre-service teacher. TESL-EJ 9, 1-30.

Borg, S. (2015). Teacher cognition and language education: Research and practice. London: Bloomsbury.

Bryman, A. (2008). Social research methods (3rd ed). Oxford, UK: Oxford University Press

Cabaroglu, N., \& Roberts, J. (2000). Development in student teachers' pre-existing beliefs during a 1-year PGCE programme. System, 28(5), 387-402. https://doi.org/10.1016/S0346-251X(00)00019-1

Corbin, J., \& Strauss, A. (2008). Basics of qualitative research: Techniques to developing grounded theory (3rd Ed.). Los Angeles, CA: Sage. https://doi.org/10.4135/9781452230153

Creswell, J. W. (2012). Educational research: Planning, conducting, and evaluating quantitative and qualitative research (4th ed.). Boston, MA: Pearson.

Debreli, E. (2016). Pre-service Teachers' Belief Change and Practical Knowledge Development during the Course of 
Practicum. Journal of Education and Training Studies, 4(7), 37-47. https://doi.org/10.11114/jets.v4i7.1513

Gebhard, J. (2009). The practicum. In A. Burns, \& J. C. Richards (Eds.), The Cambridge guide to second language teacher education (pp. 250-258). New York: Cambridge University Press.

Gürsoy, E. (2013). What is effective in forming our beliefs: Experience or education? Procedia - Social and Behavioral Sciences, 70, 763-770. https://doi.org/10.1016/j.sbspro.2013.01.121

Jamalzadeg, M., \& Shahsavar, Z. (2015). The Effects of Contextual Factors On Teacher's Beliefs And Practices. 2nd GLOBAL CONFERENCE on LINGUISTICS and FOREIGN LANGUAGE TEACHING, LINELT-2014, Dubai United Arab Emirates, Dec. 11-13 2014. Procedia-Social and Behavioral Sciences, 192. 166-171. https://doi.org/10.1016/j.sbspro.2015.06.024

Kagan, D. (1992). Implications of research on teacher beliefs. Educational Psychologists, 27(1), 65-90. https://doi.org/10.1207/s15326985ep2701_6

Kavanoz, S., Yüksel, G. H., \& Varol, B. (2017). Evolvement of Pre-service Language Teachers' Beliefs Through Teacher Education. International Journal of Progressive Education, 13(1), 119-135.

Mattheoudakis, M. (2007). Tracking changes in pre-service EFL teacher beliefs in Greece: A longitudinal study. Teaching and Teacher Education, 23, 1272- 1288. https://doi.org/10.1016/j.tate.2006.06.001

Paakkari, L., Tynjälä, P., Torppa, M., Villberg, J., \& Kannas, L. (2015). The development and alignment of pedagogical conceptions of health education. Teaching and Teacher Education, 49, 11-21. https://doi.org/10.1016/j.tate.2015.02.005

Pajares M. F. (1992). Teachers' beliefs and educational research: Cleaning up a messy construct. Review of Educational Research, 62(3), 307-332. https://doi.org/10.3102/00346543062003307

Peacock M. (2001). Pre-service ESL teachers' beliefs about second language learning: a longitudinal study. System, 29(1), 177-195. https://doi.org/10.1016/S0346-251X(01)00010-0

Razavipour, K., \& Khojastehmehr, R. (2017). Pre-service Language Teachers' Cognitions about Language Learning/teaching and Cognition Refinements through a Reflection-oriented Practicum Iranian Journal of Applied Linguistics (IJAL), 20(1), 185-217. https://doi.org/10.29252/ijal.20.1.185

Richards, J. C., \& Lockhart, C. (1994). Reflective Teaching in Second Language Classrooms. Cambridge: Cambridge University Press. Richards, J. C. (1994). Teacher thinking and foreign language teaching. The Language Teacher, 18(8), 31- 34. https://doi.org/10.1017/CBO9780511667169

Sheridan, L. (2016). Examining Changes in Pre-service Teachers' Beliefs of Pedagogy. Australian Journal of Teacher Education, 41(3). https://doi.org/10.14221/ajte.2016v41n3.1

Tang, E., Lee, J., \& Chun, C. (2012). Development of teaching beliefs and the focus of change in the process of pre-service ESL teacher education. Australian Journal of Teacher Education, 37(5), 90-107. https://doi.org/10.14221/ajte.2012v37n5.8

Tang, S. Y. F. (2004). The dynamics of school-based learning in initial teacher education. Research Papers in Education, 19(2), 185-204. https://doi.org/10.1080/02671520410001695425

Yuan, R., \& Lee, I. (2014). Pre-service teachers' changing beliefs in the teaching practicum: Three cases in an EFL context. System, 44, 1-12. https://doi.org/10.1016/j.system.2014.02.002

Zheng, H. Y. (2009). A review of research on EFL pre-service teachers' beliefs and practices. Journal of Cambridge Studies, 4(1), 73-81.

\section{Copyrights}

Copyright for this article is retained by the author(s), with first publication rights granted to the journal.

This is an open-access article distributed under the terms and conditions of the Creative Commons Attribution license which permits unrestricted use, distribution, and reproduction in any medium, provided the original work is properly cited. 